\title{
A 10 Year Retrospective of Help Desk Satisfaction for High Technology Equipment Shows Little Consistency
}

\author{
William Bleuel \\ Graziadio School of Business and Management, Pepperdine University, USA
}

Copyright $\bigcirc 2016$ by authors, all rights reserved. Authors agree that this article remains permanently open access under the terms of the Creative Commons Attribution License 4.0 International License

\begin{abstract}
This study presents the results of 10 years of telephone surveys of customers of high technology equipment (2005 through 2014) supported locally in the United States, United Kingdom, France, Germany Italy and Spain. The study has three objectives. The first objective is to determine whether there has been a trend in customer satisfaction in the 10 year period. The second objective was to determine whether the key drivers (areas most important to the customers) were consistent over time. The third objective was to determine if the drivers were the same in all countries studied. In general, the study showed that there is no significant trend in customer satisfaction over the 10 year study and that the key drivers were not consistent over time and that customers in all countries had different support priorities.
\end{abstract}

Keywords Customer Satisfaction, Help Desks, Technical Support, High Technology Service, Multinational Service

\section{Introduction}

The high technology has recognized the need for excellent customer support and has used the Computer Technology Industry Association (CompTIA) to create and manage a benchmark that will provide an accurate, reliable metric for the purpose of assessing the level of support of their products in the areas of Help Desk, Field Service and Depot Repair.

During this 10 year period $(2005-2014)$ the concern has been that customer requirements may have changed which might influence future purchasing decisions. Many technology companies in the past have managed their help desk operation by focusing on efficiency and cost reductions (treating their help desk as a cost center). Companies are finding that the cost of losing customers may be greater than the savings they have achieved through efficiency and cost decisions in the help desk operations. A number of technology companies that have taken their help desk operations to an offshore center are reconsidering their decision.

There are companies that have taken steps to reduce costs and facility expenses by using skilled labor while allowing them to work at home. The primary objective is to provide product supp011that is acceptable to their customers and supports a high level of satisfaction.

\section{Literature Review}

The work of Blodgett, Hill \& Tax, (1997) [1], provides an appropriate lens to examine and understand the complexity of the customer service process. They argue there is no single, comprehensive theory of service failure complaint behavior. In fact, market researchers have studied consumer satisfaction and dissatisfaction extensively for decades (Oliver 1980 [2]). More recent studies have shown that customer satisfaction and dissatisfaction is a reliable predictor of brand loyalty and repeated purchase intentions (Bearden \& Teel 1983 [3], Swinyard and Whitlark, 1994 [4]).

There have been some studies that point out at least one way that organizations can differentiate their offerings is through customer service (Hocutt, Chakraborty \& Mowen, 1997, pgs 457-463 [5]) using justice theory. They suggest that justice theory can provide a perspective to examine conflict situations that customers find themselves in after complaints with service providers. It was (Homburg and Furst 2005 [6]) that showed that customer satisfaction is influenced by the combination of all three dimensions of justice. For this paper, the three dimensions of justice are referred to as (i) the interpersonal treatment between the company and the customer e.g. the help desk personnel, (ii) the policies and procedures used by the company to do with the customer, and finally (iii) the perceived fairness of the outcomes (solutions to the customer problem) to the customer all seem to have a significant influence on customer satisfaction. Moorman (1991) [7] noticed the interpersonal treatment is a significant component of customer satisfaction. The importance of fairness and 
procedures that were followed during the complaint process were examined by Siders and Barry (1998) [8]. Customer service for technology problems seems to track the complaint management process and has been shown to impact repurchase intention as well as satisfaction. If users can quickly identify the natu re their problems they're likely to continue to use the product (Desousa, Awazu \& Ramaprasad 2004 [9]). However, during the service process the negative effect of a dissatisfying experience was twice as great as a positive effect of a satisfying experience (Swinyard and Whitlark, 1994 [4]). This was followed up by work (Maxham and Netemeyer, 2002 [10]) that asserted that the losses from a dissatisfying experience weigh much more heavily than gains in the mind of customers.

In general the literature suggests that the customer experience during the service process that occurs during a helpdesk activity can dramatically impact customer satisfaction or, conversely customer dissatisfaction. Looking at the customer complaint process from the three elements of justice suggests that performance of customer service will affect the level of satisfaction which will in tum affect the customer decision to repurchase the same product from the same technology provider.

This study was designed to determine what trends, if any, had occurred over the 10 year period from 2005 through 2014 for help desks serving the high technology industry and the processes that affected satisfaction.

\section{Methodology}

This study has been conducted to examine customer satisfaction for multinational companies in the high-technology industry. Each company in the study is a member of the Computer Technology Industry Association (CompTIA) benchmark. Customer surveys were performed in the countries. The equipment was located and was taken iPhone with people with local language. The study was based on 10 years of telephone interviews.

The primary purpose of the study was to test the first research hypothesis that the measures of customer satisfaction show no change over the ten year period for customers in United States, United Kingdom, France, Germany, Italy and Spain. The alternative hypothesis is that there has been a change.

The second purpose of the study was to determine (second research hypothesis) if the key drivers to overall satisfaction were consistent over the 10 years. The alternative hypothesis would be that the drivers of overall satisfaction were changing over this 10 year timeframe of 2005 through 2014.

The third purpose was to determine if the drivers of overall satisfaction were different for different countries (third research hypothesis).

There are a number of assumptions that have been made in order to complete this analysis. The first assumption is that the companies in the benchmark are all providing helpdesk service in all six countries noted above.

A second assumption is that the companies and products in the benchmark have products with approximately the same level technology complexity in their product so that all products can be considered similar.

All questions used in the benchmark survey used a five point Likert scale. The following scale anchors were used:

\begin{tabular}{|c|c|}
\hline Very dissatisfied & 1 \\
\hline Dissatisfied & 2 \\
\hline Neither Satisfied nor dissatisfied & 3 \\
\hline Satisfied & 4 \\
\hline Very Satisfied & 5 \\
\hline
\end{tabular}

Chart 1: Likert scale used in survey

The average values shown on the charts represent the average value of the "overall satisfaction" question. The same survey company (Service 800) has taken all the measurements for the entire 10 year period using the same survey instrument adapted to the local language for each country so that local idioms could be used to clarify the answers.

A third assumption is that cultural influence will be minimal since these products are technology based and all users have been trained by the product companies which are all multinational providing world-wide support. With this assumption is the complementary assumption that the Likert scale values will have similar (if not identical) interpretations in all six of the countries.

The arithmetic average was used to identify the performance of the help desks each year. While statistically the arithmetic average is not considered appropriate as a valid measure, companies using the CompTIA benchmark identify with this measure and consider it useful and often rely on it to make strategic decisions (especially with respect to trending).

There were several items that were not covered in this study. The benchmark, which has a history of over 20 years, has been restricted to a review of the last 10 years. In order to test the research hypothesis the question was "overall satisfaction". Since the various companies had additional questions for their specific equipment, the only question that was consistent for all companies was the "overall satisfaction" question. Other questions in the survey were not considered in the hypotheses tests except some performance questions that were used to detect the drivers of overall satisfaction for each year. The questions that were used to detect the drivers excluded those unique questions that some companies added to the base survey.

Since all the companies in the benchmark are multinational, it was assumed that all customers had approximately the same skill level for operating the equipment. In addition, it was assumed that all the customers 
had approximately the same level of training on the equipment. Since the sample sizes from each country in every year are each in excess of 1000, the use of the arithmetic average should be representative of the customer base. The actual sample size by country for each year is shown in table 1 following:

Table 1. Sample sizes by country and year

\begin{tabular}{|c|c|c|c|c|c|c|}
\hline Year & US & UK & France & Germany & Italy & Spain \\
\hline 2005 & 55553 & 6075 & 6511 & 5252 & 2339 & 3614 \\
\hline 2006 & 34884 & 5656 & 6230 & 6563 & 2695 & 6659 \\
\hline 2007 & 43774 & 8092 & 6653 & 8940 & 3818 & 3904 \\
\hline 2008 & 52865 & 8507 & 7576 & 10953 & 4400 & 5173 \\
\hline 2009 & 47110 & 7819 & 6251 & 7979 & 3542 & 3977 \\
\hline 2010 & 20000 & 5300 & 4896 & 1481 & 2634 & 2723 \\
\hline 2011 & 29808 & 3262 & 2691 & 3886 & 1705 & 2305 \\
\hline 2012 & 41031 & 3021 & 3078 & 3564 & 2402 & 2029 \\
\hline 2013 & 19061 & 4326 & 2990 & 2348 & 2952 & 2410 \\
\hline 2014 & 18060 & 4182 & 3102 & 1860 & $\underline{2240}$ & 1856 \\
\hline
\end{tabular}

A random sample is drawn from all the service events provided by each company that is supplied each week. The sample size is based on providing a minimum of $95 \%$ confidence for each metric in the benchmark.

\section{Analysis}

A line chart is presented in Chart 2 that shows the average satisfaction for each of the six countries for the 10 year benchmark. A visual review of the chart suggests that the range of average values has a slight positive trend.
Table 2 below is provided that shows the actual average score for each country for each year.

Table 2. Average score for "Overall Satisfaction"

\begin{tabular}{|c|c|c|c|c|c|c|}
\hline Year & USA & UK & France & Germany & Italy & Spain \\
\hline 2005 & 4.35 & 4.02 & 4.03 & 4.05 & 4.16 & 4.20 \\
\hline 2006 & 4.37 & 4.14 & 4.02 & 4.17 & 4.09 & 4.13 \\
\hline 2007 & 4.25 & 3.97 & 4.15 & 3.96 & 4.04 & 4.28 \\
\hline 2008 & 4.35 & 4.36 & 3.75 & 3.96 & 4.15 & 4.34 \\
\hline 2009 & 4.39 & 4.21 & 4.16 & 4.02 & 4.30 & 4.12 \\
\hline 2010 & 4.30 & 4.31 & 4.22 & 3.99 & 4.30 & 4.11 \\
\hline 2011 & 4.41 & 4.36 & 4.16 & 3.99 & 4.32 & 4.15 \\
\hline 2012 & 4.65 & 4.41 & 4.12 & 4.11 & 4.30 & 4.14 \\
\hline 2013 & 4.43 & 4.21 & 4.13 & 4.13 & 4.37 & 4.32 \\
\hline 2014 & 4.45 & 4.19 & 4.15 & 4.19 & 4.41 & 4.41 \\
\hline
\end{tabular}

When a regression was performed on each country for the 10 years the following results were obtained as shown in Table 3 below:

Table 3. Results of regression analysis

\begin{tabular}{|c|c|c|c|}
\hline Country & $\begin{array}{c}\text { Change per } \\
\text { year }\end{array}$ & R-Square & $\begin{array}{c}\text { Probability Due to Chance } \\
\text { Type I error }\end{array}$ \\
\hline USA & 0.02 & 0.338 & 0.078 \\
\hline UK & 0.03 & 0.293 & 0.106 \\
\hline France & 0.02 & 0.177 & 0.281 \\
\hline Germany & 0.01 & 0.143 & 0.226 \\
\hline Italy* & 0.04 & 0.786 & 0.001 \\
\hline Spain & 0.01 & 0.108 & 0.355 \\
\hline
\end{tabular}

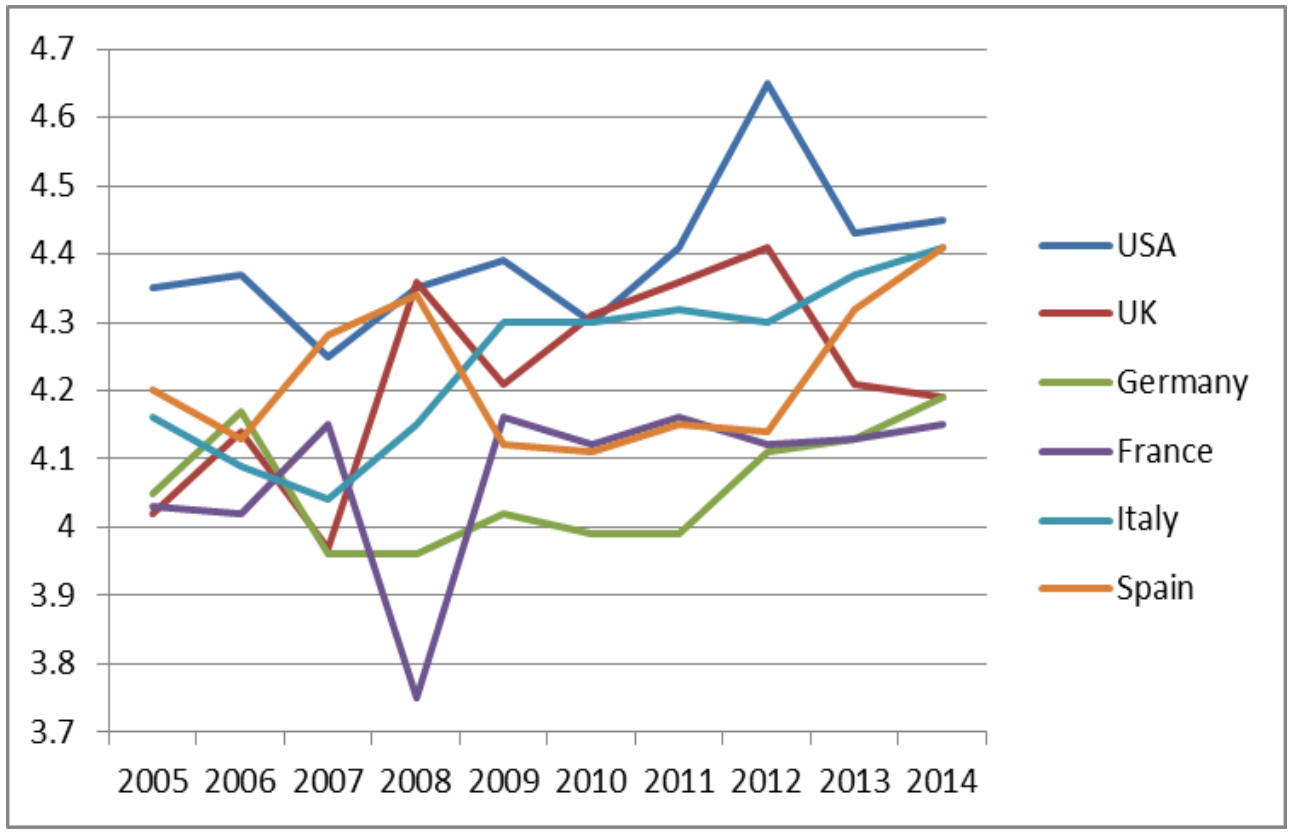

Chart 2: Trends for all countries for 10 years 
Italy is the only country with a statistically significant trend. All other countries have probabilities greater than $5 \%$ that the regression is due to chance.

Table 4 below presents the driver question with the highest correlation to the question relating to "Overall Satisfaction".

Table 4. Driver with highest correlation to "Overall Satisfaction"

\begin{tabular}{|c|c|c|c|c|c|c|}
\hline Year & USA & UK & France & Germany & Italy & Spain \\
\hline 2005 & Tech & Comp & Comp & Comp & Comm & Comm \\
\hline 2006 & Tech & Comm & Comp & Comp & Comp & Comp \\
\hline 2007 & Tech & Fix & Comp & Fix & Comp & Prof \\
\hline 2008 & Tech & Prod & Fix & Prod & Comp & Ease \\
\hline 2009 & Tech & Fix & Fix & Fix & Comp & Tech \\
\hline 2010 & Fix & Fix & Fix & Fix & Comp & Fix \\
\hline 2011 & Fix & Fix & Comp & Fix & Prod & Comp \\
\hline 2012 & Comm & Fix & Fix & Prof & Tech & Fix \\
\hline 2013 & Comm & Fix & Tech & Ease & Tech & Tech \\
\hline 2014 & Comm & Fix & Ease & Prof & Tech & Tech \\
\hline
\end{tabular}

The above abbreviations are taken from the actual survey questions used to indicate the drivers of "Overall Satisfaction" as shown below:

- (Ease) the ease of requesting help

- (Fix) the time it took us to provide a solution

- (Comp) the completeness of our solution

- (Prod) the quality of our product

- (Tech) the technical ability of our technician

- (Prof) the professionalism of our technician

- (Comm) how well we kept you informed

A review of the primary drivers indicates there is no consistent driver for any of the six countries for the 10 year period. Further, there is no driver that is consistent across all 6 countries in any year. The general observation is that the primary driver is not consistent for the countries in any year nor is it consistent for any one country for the entire 10 years.

\section{Discussion and Future Research Recommendations}

Some of the general conclusions that are apparent from the analysis are:

1. There has been no statistical change in help desk satisfaction over the last 10 years.

2. The major drivers of satisfaction have remained relatively constant but seem to vary by country and by year.

3. When all the countries are viewed together, there is a general trend that suggests (not statistically) an average increase of average Overall Satisfaction of about 0.02 units per year.

4. Customer satisfaction is relatively stable.

5. The statistical drivers of Overall Satisfaction are not consistent from country-to-country or from year-to-year.

When the data are applied to the three hypotheses the results are:

Hypothesis I: There is no trend in help desk satisfaction for the 10 years cannot be rejected (with the exception of Italy).

Hypothesis II: The key drivers were the same for all 10 years is rejected.

As noted in the previous table 4 the drivers changed from year-to-year for each country.

Hypothesis III: The drivers of satisfaction were the same for all six countries is rejected. The drivers were never the same for all six countries for any one year. This condition was true for each of the 10 years.

\section{Opportunities for Future Research}

There are a number of opportunities for future research using the data in the CompTIA database. Some of the possible suggestions using the data in this analysis include:

1. Examine the statistics of the Overall Satisfaction question from the perspective of the percentage that scored either a 1 or 2 on the Likert scale. This might provide insight to the dissatisfiers in each country.

2. Examine the statistics of the Overall Satisfaction question by individual company to test whether or not each company performed with equal levels of Overall Satisfaction.

3. Expand the analyses to include representative countries to examine the world-wide trends in Help Desk.

4. Add a cultural variable such as Hofstede's cultural measure to detect the influence of culture on Overall Satisfaction and the influence of the drivers of satisfaction.

5. Expand the analysis to consider the covariance of the driver variables.

6. The use of factor analysis might present a red uced number of drivers with stronger statistical relationships.

This study could also be expanded to include the Field Service and Depot Repair databases. Some possible suggestions using the additional databases could include the following analyses:

1. Determine if the trends in Field Service and Depot Repair are similar to the Help Desk trends.

2. Determine whether the drivers of satisfaction are the same for all three types of service.

3. Determine if the dissatisfiers are similar for each of three types of service.

4. Since the CompTIA database includes approximately 80 countries, the research in each of these areas could be expanded geographically for 
each of the three services and perform the suggested analyses noted above for other groups/combinations of countries.

The use of these satisfaction data provides a rich source of information that should be used on a regular basis to validate service strategies and operational performance.

\section{REFERENCES}

[1] Blodgett, J. G., Hill. D. J. and Tax, S. S. (1997) The effects of distributed, procedural, and interactional justice on postcomplaint behavior, Journal of Retailing, Vol 73, No. Two, pages $185-210$.

[2] Oliver, R. L., Satisfaction: A Behavioral Perspective on the Consumer, McGraw-Hill, Boston, MA

[3] Bearden, W. O., and Teel, J. E. (1983) Selected determinants of consumer satisfaction and complaint reports, Journal of Marketing Research, Vol. 20, No. One, pages 21-28

[4] Swinyard, W., and Whitlark, D., (1994) The effect of consumer dissatisfaction on store re-purchase intentions: a little goes a long way. The International Review of Retail, Distribution and Consumer Research pgs. 329-344

[5] Hocutt, M., Chakraborty, G., \& Mowen, J., (1997) The Impact of Perceived Justice on Customer Satisfaction, and Intention to Complain in a Service Recovery, Advances in Consumer Research, Vol 24, pages 457-463

[6] Homburg, C., Furst, A., (2005) How organizational complaint handling drives customer loyalty: an analysis of the mechanistic and the organic approach, Journal of Marketing, Vol. 69, pages 95-114

[7] Moorman, C., MacInnes, D., \& Jaworski, B. (1991) Enhancing and Measuring Consumers' Motivation, Opportunity and Ability to Process Brand Information from Ads, Journal of Marketing Vol 55, pages 32-53.

[8] Seiders, K., Berry, L.L., (1998) Service fairness: what is it and why it matters , Academy of Management Executive, Vol.12, No. 2, pages 8-20

[9] Desousa, A. C., Awazu, Y. and Ramaprasad, A. (2004) Modifications and innovations to technology artifacts , Technovation, Vol. 27, No. F, pages 204-220.

[10] Maxham III, J. G. and Netemeyer, R. G. (2002) A longitudinal study of complaint customers evaluations of multiple service failures and recovery efforts, Journal of marketing, Vol. 66, pages $57-71$.

[11] Mohr, L.A., Bitner, M.J., (1995) The role of employee effort in satisfaction with service transactions, Journal of Business Research, Vol. 32, pages 239- 252

[12] Anderson, E.W., Sullivan, M.W. (1993) The antecedents and consequences of customer satisfaction for firms, Marketing Science, Vol.12, No. 2 pages 125-143.

[13] Churchill Jr., G. A. and Surprenant, C. (1982) An investigation into the determinants of consumer satisfaction, Journal of marketing research, Vol. 19, No. F, pages 490-504.

[14] Fornell, C. and Wernerfelt, B. (1987) Defensive marketing strategy by customer complaint management: a theoretical analysis, Journal of Marketing Research, Vol. 24, No. F, pages 337-346.

[15] Jha, S., Sangareddy, S. R. P., Desousa, K.C., Seo, Dongback and Ye, Chen Ye 2010, Impact of complaint management on repurchase intention of consumer technologies: employing the justice theory lens, International Journal of Product Development, Vol. 12, No. 3/i, pages 352-371.

[16] Goodwin, C., Ross, I., (1992) Consumer responses to service failures: influence of procedural and interactional fairness perceptions, Journal of Business Research, volume 25, pages $149-163$

[17] Tax, S. S., Brown, S. W. and Chandrashekaran, M. (1998) Customer evaluations of service complaint experiences: implications for relationship marketing, Journal of Marketing, Vol. 62, pages 60-76.

[18] Cunen, M.T., Folkes, V.S. (1987) Attitudinal influences on consumer's desire to communicate about products, Psychology and Marketing, Vol. 4, pages 31-45.

[19] Folkes, V.S., (1984) Consumer reactions to product failure: an attributional approach, Journal of Consumer Research, Vol. 10, No. 4, pages 398-409.

[20] Hart, C.W.L., Heskett, J.L., and Sasser Jr. W.E., (1990), The profitable art of service recovery, Harvard business review, Vol. 68, No. 4, pages 148-156.

[21] Hess, R.L., Ganesan, S., and Klein, N.M., (2003) Service failure and recovery: the impact of relationship factors on customer satisfaction, Journal of the Academy of marketing science, Vol. 31, No. 2, pages 127- 145.

[22] Richins, M.L., (1987) A multivariate analysis of responses to dissatisfaction, Journal of Academy of marketing science, Vol. 15 , No. 3, pages $24-31$

[23] Smith, A.K., Boltoon, R.N., and Wagner, J., (1999) A model of customer satisfaction with service encounters involving failure and recovery, Journal of marketing research, Vol. 36, No. 3, page 356-372.

[24] Hair Jr., J.F. Anderson, R.E. Tatham, R.I., and Black, W.C., (1998) Multivariate Data Analysis, Macmillan Publishing Co., New York 